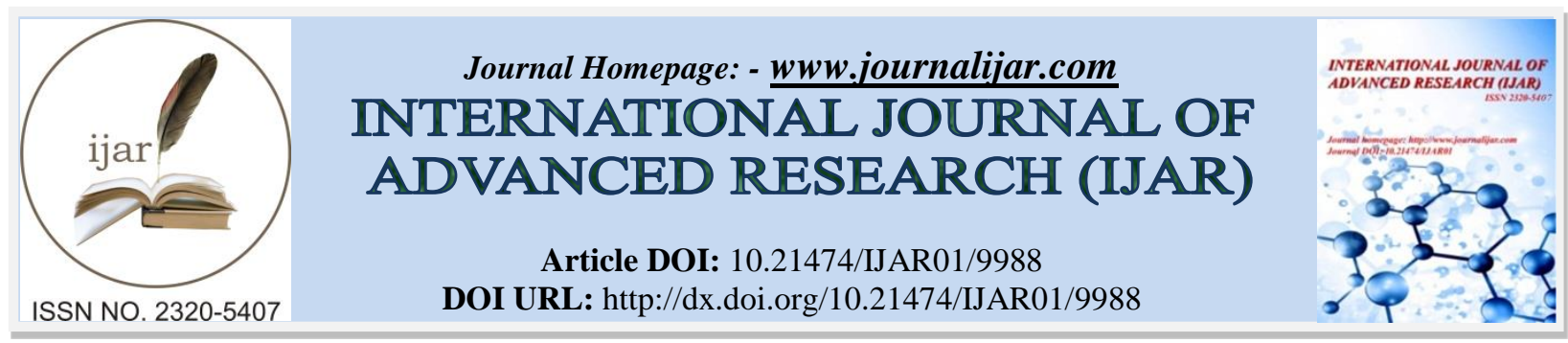

RESEARCH ARTICLE

\title{
APPLICATION OF ARTIFICIAL INTELLIGENCE FOR SUCCESSFUL STRATEGY IMPLEMENTATION IN INDIA'S BANKING SECTOR.
}

\author{
Ms. Bhavna Agarwal, Dr. Himanshu Agarwal and Dr. Parvez Talib. \\ Aligarh Muslim University, Aligarh; D. N. (pg) college, C.C.S. University, Meerut; Aligarh Muslim University, \\ Aligarh; India.
}

\section{Manuscript Info}

Manuscript History

Received: 05 September 2019

Final Accepted: 07 October 2019

Published: November 2019

Key words:-

Artificial intelligence, banking, customer experience, digital technology, economy, industry 4.0, strategy implementation.

\begin{abstract}
Banks have been already offering a wide variety of products and services, integrated with technology and automation, the most familiar being ATM machines all around us. Now moving to the next level in the present Industry 4.0 era, Banking sector is all set to amplify its strategy implementation by leveraging latest digital technologies so that its customers may experience swift and secure processing of transactions. This study examined the evolution, adoption, implementation and future opportunities of leveraging Artificial Intelligence (AI) for successful strategy implementation in India's banking sector. In pursuance of this study, authors reviewed extensive literature, explored secondary data about the research work done on 'Artificial Intelligence in Banking Sector' to find out the current status of research as well as practical application of AI in various aspects of banking strategies e.g. surveillance, fraud detection, ensuring compliances, credit assessment, customer service, handling monotonous voluminous tasks etc. in general and focusses on recent developments in context of India's banking sector, urging banking leadership to shift their focus proactively towards leveraging AI with an objective to bring in delight for customers.
\end{abstract}

Copy Right, IJAR, 2019. All rights reserved.

\section{Introduction:-}

Business strategies are concerned with swift decision making, business promotion, industry growth, profitability, productivity, cost reduction, capital formation, investments, market share, efficiency, effectiveness, customer satisfaction, their retention, achieving \& managing customer delight, optimum utilization of resources, enriched products \& services so that they may remain competitive. In the present Industry 4.0 era, all of these areas of business get seriously influenced by technological innovations or absence thereof. This paper is an attempt to establish connect between successful strategy implementation and latest digital technologies in these business areas with specific reference to India's Banking sector. Since banks are pivotal for economic development of nation's economy and India is moving ahead with a target to achieve $\$ 5$ trillion economy by the year 2024 , so a paradigm shift is bound to take place in its banking sector, refining their strategy implementation by leveraging latest digital technologies, serving wider goals of balanced development of the entire nation. The most common example of application of digital technology being virtual assistants enabled by banks on their websites. In this study author explores more such applications of technology, its evolution, implementation and future opportunities with specific

Corresponding Author:-Ms. Bhavna Agarwal.

Address:-Aligarh Muslim University, Aligarh. India. 
focus being on Artificial Intelligence (AI) as a collaborator for successful strategy implementation in India's banking sector.

Digital Technology is a crucial element of Information Technology (IT) strategy of every banking organization operating in present agile Industry 4.0 era as every bank needs visibility into its people, customers, processes, tools, utilization trends thereof and strategic goals i.e. ensuring optimum utilization of IT resource - consequent saving of money, while at the same time offering world class services to its customers, hence initially banking IT strategies adopted automation of data collection, analysis thereof and intelligent reporting with an objective of achieving aforesaid goals. And now its time to deploy digital technology like AI having insightful ability of interconnecting large number of processing elements, resolving problems by processing information similar to natural human brain and to successfully implement intended strategies.

India's banking system can get developed and integrated with the international market by leveraging such technologies. Researchers take up this study with an objective to examine the state of affairs of AI in India's Banking sector and research conducted thereon in order to facilitate banking leadership in successful execution of their strategies. Consequently, researchers framed few specific objectives and outlined the scope of this study. The scope of this study contextually is focused on evolution, implementation and future opportunities associated with proactive utilization of AI in India's banking sector, thus necessitating current status of the research in this area to be explored, along with practical applications achieved till now and forthcoming opportunities via proactive utilization of AI. Based on this study, Researcher presents several areas of India's banking sector where AI has made its way and much more which can be achieved further in this business area.

\section{Research Objective:-}

Rich literature is available about evolution, application and adoption of latest AI innovations as a strategic key success factor in developed countries. However, in India, it has still a long way to go before technology gets integrated with day-to-day activities like banking. Hence this study is undertaken with specific focus on refining and empowering strategy implementation in India's Banking sector by leveraging AI. Specific objectives of this study are:

1. To identify the research work conducted about concept $\&$ application of AI in banking sector.

2. To examine the state of affairs of AI's application in india's banking sector.

3. To explore capabilities of AI to deliver differentiated results for successful strategy implementation in india's banking sector.

4. To draw the focus of banking leadership from a reactive to proactive adoption of AI for successful execution of their strategies, aligned to their vision.

\section{Overview Of Banking Sector And Application Of Artificial Intelligence In Its Strategy Implementation:-}

The recent major events like demonetization and government sponsored initiatives of developing digital India have not only encouraged India's economy to become cashless, but also brought in a massive amount of data in banks, demanding quick, accurate and consistent updation \& maintenance of records. Banking sector had long back made computers an integral part of its operations and since 1990's, automation became key pillar to modern banking e.g. money withdrawal, transfer of funds, ordering cheque books etc. (Moin \& Ahmed, 2012) and now due to huge changes in economy, increased work volume, major shifts in consumer preferences, customer objectives, growing population of youngsters, new competitors, regulatory requirements and corresponding need to have robust access management \& secured banking environment for transactions, banking sector has started leveraging AI to digitize the tedious manual tasks, shaping future of economy, reducing strategy cycle, implementing its strategies successfully, thus transforming traditional branch banking into mobile / online banking, pioneered by private sector banks of India (Sabharwal, 2014). This initiative is adequately supported by technological improvements in computing, its storage, mobile devices and wide spread usage of social media. 'Digital India' focuses on transforming India into a digitally empowered and knowledge economy. The recent developments in Cashless Commerce in India shows that there is an urgent need of Digital Payments in India (Sharma \& Agarwal, 2018).

In the present day's significant transformation era, businesses are relying heavily on interconnectivity, automation, machine learning and real time data processing for conjunction of physical production / services with digital technologies. This transition is known as Industry 4.0 i.e. the fourth revolution in industries. This is an ideal stage 
for integrating digital technologies e.g. AI with banking operations also, which offers huge potentials of harvesting profits for Banks and provides reduced reaction time (up to milliseconds) for its customers. As a result, both the parties i.e. customer as well as Banks will increasingly be interested in leveraging AI for enabling fruitful, swift and flawless operations. When technology is managed correctly, it fosters a change of state, progress and improved standard of service delivery.

This concept called AI emerged in technology landscape when a model of artificial neurons was proposed by Warren McCulloch and Walter Pitts in 1943, followed by first neural network computer built in 1951 by Marvin Minsky and Dean Edmonds. The term "Artificial Intelligence" was coined in 1955 by Prof. John McCarthy of Sandford University, one of the "Founding Fathers" of AI, defining it as "the science and engineering of making intelligent machines". In 1960, US Department of Defense started training their computers to act like human logical powers (Russell \& Norvig, 2003). AI is a discipline of digital technologies which embeds human intelligence into machines by designing and applying algorithms enabling machines to learn, adapt \& develop solutions on their own from interpretation of data over a period of time so that tasks like strategizing, problem solving, reasoning, learning, speech / visual recognition, natural language processing etc. may be managed mechanically (Bellman, 1978). AI is defined as enabling machines to perform such acts which shall require intelligence if performed by human (Kurzweil, 1990), using computation that can perceive, reason \& act (Winston, 1992). AI made a significant leap in technological advancement from robotics towards machine learning and predictive analysis. R1 -- The first successful commercial expert system started operating in 1980s at Digital Equipment Corporation (Russel \& Norvig, 2003) and its commercial applications started flooding markets since 2005, introducing products like Siri, Cortana, Alexa, Watson etc. developed respectively by Apple, Microsoft, Amazon \& IBM (Russell \& Norvig, 2003). Using Computer languages like Prolog, $\mathrm{C} / \mathrm{C}++$, Java \& Python, AI enables computers, robots and software to think intelligently similar to human (SINDU, 2019). In a survey conducted by Infosys on 1600 business executives in decision making roles, 75\% executives regarded AI as fundamental to the success of organization's strategy. Organizations who have already employed AI, they expect approx. 39 per cent increase in revenue by year 2020. Forbes magazine claimed that application of AI can reduce the operational cost of organizations up to 22 per cent. So it is but obvious that banking sector has also started integrating AI with its strategy implementation to gain competitive edge in terms of swift, error free, effective and efficient customer services while at the same time reducing branch visits to a great extent. Benefits of $\mathrm{AI}$ are derived from its inter-connected building blocks working in cohesion, as summarized below:

1. Machine Learning (ML) creates intelligent machines which analyze data, identify patterns and adjust its program / logic dynamically on its own to respond in accordance of data, without being explicitly programmed. Use Cases: Customer Service, Wealth Management, Risk Management, Fraud Detection

2. Deep Learning (DL) creates an artificial replica of human brain and works with non-linear approach of analyzing data, thus enabling better decision making closer to the precision of human brain.

Use Cases: Fraud detection, Identifying new business opportunities working within banking environment as well as on larger social media platforms

3. Natural Language Processing (NLP) enables machines to understand and analyze sentiments of human based on their language (text \& speech) and to respond accordingly.

Use Cases: Feedback about an organizations products, services \& offerings

4. Speech Recognition, a sub-set of NLP, enables machine to understand human spoken language based on Acoustic \& Language modeling algorithms.

Use Cases: Voice Banking, Authentication based on customers' unique voice patters

5. Natural Language Generation (NLG) enables machines to generate natural language so that machine may interact with human in their natural language.

Use Cases: Machines can communicate to human customers in human language in an intelligent and understandable manner

6. Visual Recognition employs DL to view, understand and identify visual images, match it with larger data sets and returns a matching value for the same.

Use Cases: Image recognition, Deposit of cheques, payment of bills based of its images

7. Optical Character Recognition enables conversion of handwritten, typed and printed text into machine encoded text so that machines may understand the same.

Use Cases: Conversion of physical documents into mechanical fields in computer systems 


\section{Research Methodology:-}

In this study, authors attempted to study the secondary data available in published literature e.g. research papers, books, websites, newspapers etc. Secondary data is one which is collected by other scholars and has already passed through statistical processes. Literature review is essential for every research work, as it assesses and analyzes the relevant literature for identifying the areas which need strengthening in the field of study. Accordingly extensive literature review was carried out from the renowned published literature available on the most extensive abstract and citation database e.g. J Gate, ProQuest, Ebsco, internet website, newspaper etc. about the area of interest in this study so that the research objectives may be explored adequately. Researcher performed holistic qualitative analysis on this data to establish the availability of adequate literature about evolution of AI and current state of affairs of its application. In this process, researcher thoroughly analyzed various research papers, crosschecked \& corroborated the facts, utilizing qualitative contents across databases to carry out this in-depth detailed study in real-life context. After reviewing the same, evolution of AI and its existing implementation practices have been identified with specific reference to the banking sector, current state of affairs in India's context has been examined and its capabilities have been explored. Researchers discussed the same and made own observations on the relevant aspects for drawing banking leadership's approach from reactive to proactively leveraging AI for achieving successful implementation of their strategies while staying focused on their organization's vision. Researcher applied "5 Why" method to peel away through the layers of AI to identify the qualitative differentiated results it can bring in strategy implementation in India's banking sector. The most relevant and appropriate articles \& papers are cited in this paper.

\section{Literature Review:-}

For revamping the business model, Business Strategies and Technology were found to be integrated in last decade of $20^{\text {th }}$ century itself (Chester, 1994) and value of investments on technology vis-a-vis its productivity as well as economic benefits were being evaluated (Brynjolfsson \& Hitt, 2000). Ability of human brain to process information and solving problems has encouraged scientists to put similar intelligence into machines (Shachmurove, 2002). Since banks have a very significant role in economic development of a nation, so their successful strategy implementation, leveraging state-of-the-art technologies, adds value not only to their own business but to the economy and growth of the entire nation, hence banks need to keep pace with increasing expectations of today's rapidly changing environment (Brauer, 2005), aligning its strategies to ensure continuity of business, addition of customers as well as retention of existing customers (Zineldin, 2006), accordingly banks are trying various strategies to innovate products/services to achieve this (Alam \& Khokhar, 2006). A technology that can act like human, has ability to learn languages, accomplishes physical tasks, emulate human decision making (Russel \& Norvig, 2003), enables machines to carry out activities that require human intelligence (Brachman, 2006) by combining various techniques of machine learning, pattern recognition, logics \& probability theory in addition to biologically inspired models (Duch, Swaminathan, \& Meller, 2007) known as computational intelligence. Customers' faith in technologies paved the way for mobile banking payments (Donner \& Tellez, 2008) because system quality and information quality is a significant influencer on the customers' satisfaction and trust (Lee \& Chung, 2009). AI has made its way in assessment of bank performance (Fethi \& Pasiouras, 2010) and Information technology is being extensively used by banking sector across the globe (Vedapradha, Ravi, \& Jebasingh, 2016) in its operations like accounting, auditing and assurance domain, easing out some of its most challenging tasks and supporting decision making by collecting, analyzing and creating accurate financial information (Davenport, 2016). Banks are moving towards next level to create Expert Support System (ESS) and Decision Support System (DSS) to make managerial decision making more informed, consequently implementing strategies more effectively in critical areas like service quality (Castelli, Manzoni, \& Popovic, 2016), credit risk appraisal, loan defaulters, profitable investments, interest rate inflation etc. (Ghodselahi \& Amirmadhi, 2011) (Moro, Cortez , \& Paulo, 2015) (Vedapradha, Ravi, \& Jebasingh, 2016). Considering the need of dynamic systems which can understand patterns in the data of market conditions and can adjust financial strategies accordingly so that pragmatic and prompt service may be provided to the customer (Nuseibeh, 2017), research scholars have presented end-to-end Robotic Framework with detailed hardware and algorithmic aspects which can be introduced to a wide range of industries, including banking, to optimize their processes (Chakroborty, 2017). Main factors encouraging AI into banking sector are its ability of low cost production, open source system \& accessibility of the same; hence within next 3 years AI is expected to become the primary way banks interact with their customers - without depending on bank branches and physical cheque books (Sinha, 2017). India's banking sector is investing in Robotics and AI to serve its modern tech savvy customer in an efficient manner (Ayachit, 2017). Banking products have moved far ahead from the conventional banking of India (KUMAR, 2018). Application of innovative technologies by banks in implementation of their strategies to achieve efficiency is praiseworthy (Lagarde, 2018) and is expected to create their globally unified practices, policies 
and framework with the help of AI (Erdélyi \& Goldsmith, 2018). Strong positive relationship (R- coefficient = 0.859) has been observed between AI and proper record keeping (Longinus, 2018) and AI has strong potentials of transforming all banking operations (Ghurair, 2018) refining investment strategies, managing customers' data, carrying out risk assessment, curbing money laundering issues and adding value by reducing costs of money transfer while increasing accuracy levels (Sophia, 2018), thus increasing profitability, improving the quality of decisions made at different operational levels of management (VEDAPRADHA \& HARIHARAN, 2018), sparing human resources for innovating \& executing intended strategies aligned with organizations vision \& betterment of economy as a whole (Kurode, 2018). At present human employees of banks are performing many unproductive tasks of repetitive nature whereas availability of human manpower for owning creative and decision making roles is limited (Kurode, 2018).

The para above provides insight about technical, practical and strategic aspects of AI and its contribution towards business strategy to help banks for taking call to adopt or not to adopt AI. Considerable work has already been done by the scholars and much more is getting added to the knowledge repository with each passing day. One study has found that the adoption of AI in banking sector may add approx. \$1trillion to India's economy by 2035 (Lakshminarayana \& Deepthi, 2019). Reserve Bank of India has proactively promoted application of technology for implementing regulations and creating policy frameworks in India's banking sector under leadership of Dr. Raghuram Rajan and Urjit Patel (Aazhvaar, 2019). But Strategy formulation is much easier than its successful implementation. Same is the case with country like India, having huge population with high percentage of rural or non tech savvy population, impeding pace of implementing services powered by technology (Kurode, 2018).

Intgration Of Artificial Intelligence With Banking Sector:-

Based on the Literature reviewed, application of AI in banking sector can be summarized as follows:

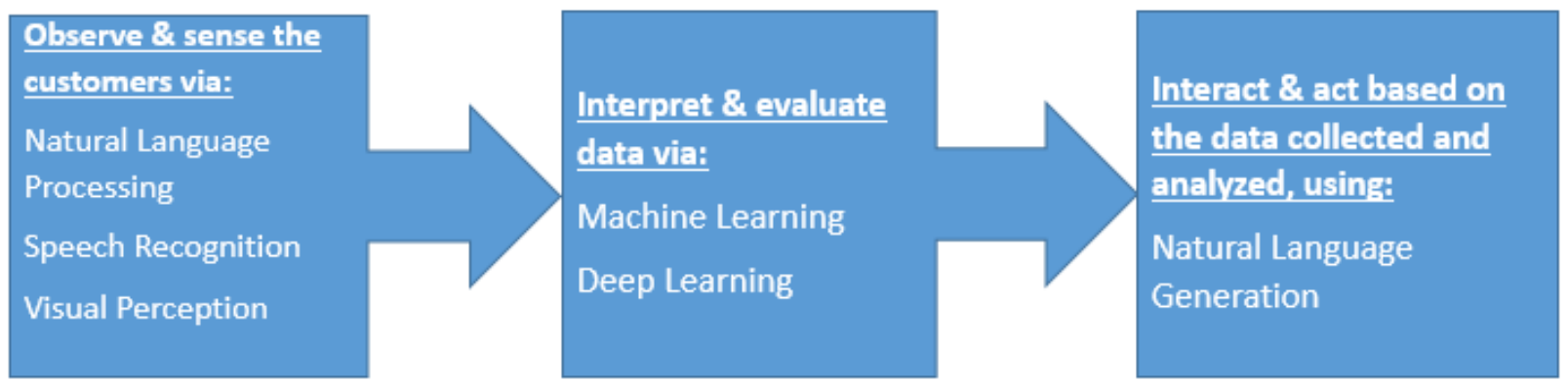

It is extremely important for banks to remain competitive and proactive in Industry 4.0 environment. They have to be dynamic, constantly taking and aligning their decisions, accelerating changes in business processes with an objective to optimize the profitability as well as service delivery. This study analyzed application of AI for achieving success in implementing strategies in the dynamic environment of banking sector, considering end-to-end activities which are assigned to these intelligent machines. Summary of several significant opportunities for banking sector to utilize AI are presented here-in-below:

1. Developing, driving and supporting execution of strategies based on data analysis and research.

2. Improving Profitability by reducing Strategy cycles, reducing costs on redundant tasks, increasing productivity, efficiency customers' loyalty and optimizing service delivery by becoming operationally lean.

3. Catering to applicable Regulations by transforming and re-engineering banking operations.

4. Supporting accurate Decision making by presenting analyzed data along with recommended results, thus assisting banking leadership.

5. Enhancing core banking solutions by operating at a much robust pace and being agile in response to market conditions, enabling banks with a better go-to market approach among different asset classes, managing customers portfolios by assessing their profile through algorithmic sorting based on research about financial institutions, loans, investments and then augmenting this data with customers' behavior to approach each customer in personalized manner.

6. Surveillance in sensitive areas by developing customized secure environment as per applicable regulatory requirements, scanning transactional \& non-transactional logs to identify suspicious activities, abnormalities in patterns, warning signs of fraud attempts, collecting evidences, analyzing data for necessary conviction and responding to that in time, thus outperforming the criminals (Ray, 2017). 
7. Physical \& Logical Access Management for Locker rooms \& designated areas can be secured based on face recognition, mandatory authentication, authorization process, generating unique service token and inbuilt anonymous continuous monitoring mechanism when user is performing the banking transactions.

8. Operational efficiency $\&$ customer delight can be achieved in labor intensive repetitive tedious, monotonous, voluminous, time consuming tasks by ensuring rationalization, standardization and swiftness in 100 percent error-free personalized \& extremely intuitive service delivery, reducing banks' turnaround time significantly.

9. Human bias and emotional interference can be reduced by intelligent machines to avoid distortion in decision making process, reducing time for business processes implementation, answering customers' queries without any frustration and self-interest of earning commission, thus boosting productivity.

10. Credit assessment and decision can be effectively managed through Personal Assistant powered by Neural Network using classification models, analyzing market conditions with reference to the lifestyle, appetite for risk, financial goals, individual portfolios, systematic pattern recognition in past behavior of customers and time series forecasting adhering to banking credit standards, thus developing successful financial strategies from banks' perspective which simultaneously result in fruitful investments from customers' perspective.

11. Error free and up-to-date record keeping, elimination of human error, handling some of the most challenging aspects of accounting, auditing and assurance domain can be managed by AI.

12. AI powered Virtual Customer Assistant \& Chat Bot engages customers in speech / text in human language, learns from their activities/interactions, understands their behavior and provides suggestions / takes action accordingly, handling all the tasks from customer on-boarding to various customer services. They operate not only within banking domain environment but outside it on wider social media and messaging platforms also, the platform which are meant for news, e-commerce and even entertainment and thus influencing customers' behavior towards banking products by conversing intelligently. Based on the set algorithms, these bots are designed intelligent enough to seamlessly handover customer dealing to a human executive at any stage when such a need arises. Learning from past data being an essential element of AI, such bots become more efficient with its increased use. Concerned bank officials can keep on enriching the data base/question bank, based on which these bots respond, in order to keep pace with latest information and wider coverage of subject matter. This combination of AI and precise human input by banks adds to customer delight by fulfilling requests, solving problems and predicting customer requirements.

13. Interactive Voice Responses (IVRs) transformation may sync with customers shifting from webpage search (Google) to the voice search (Google Assistant), enabling human-like interaction, shortening the waiting queues, minimizing dependence on call centers, KPOs \& BPOs, consequently reducing scope of human errors.

14. Manpower freed by applying AI into day-to-day tasks - including payment related jobs handled by Chat Bots, can be utilized for more value added and human centric service functions, motivating employees to up-skill and re-skill themselves for shouldering higher responsibilities. Added advantages would be to scale up the capacity during peak / emergency scenarios offering qualitative services to the customers and bank employees will be able to enjoy a better work-life balance for themselves.

\section{Leveraging Artificial Intelligence In India's Banking Sector:-}

Having traverse through the wide literature reviewed on this topic of interest, this study identified the potentials of AI for achieving successful implementation of strategies in India's banking sector because AI understands the workflow of the banking system and restructures the processes to automate the same. Practical application of AI in India's banking sector which are becoming part of day-to-day life and benefiting customers in the form of quasibanker chat bots are mentioned below:

RBI: National Payment Corporation of India (NPCI) is working to bring down the cost of electronic transactions. Institute of Development and Research in Banking Technology (IDRBT) is studying opportunities and challenges in new technology areas.

SBI: Propelled a national hackathon and now using facial recognition technology based "Chapdex" developed by winning team of the contest; chatbot "SIA" is active on SBI website to interact with customers.

HDFC: Chatbot "EVA" (Electronic Virtual Assistance) built by Senseforth AI Research, has handled the following since March, 2019:

Addressed customer queries > over 2.7 million

Interacted with unique users $>530,000$

Held conversation > 1.2 million 
ICICI Bank: It is India's first bank to deploy software robotics \& automation in over 200 business processes across various functions e.g. retail banking, treasury, HR etc. to perform repetitive, high volume tasks, reducing response time by approx. 60 per cent with accuracy being 100 per cent. Chat bot "iPal" is serving on its website.

AXIS Bank: AI \& NLP enabled app to help consumers with financial and non-financial transactions, to answer FAQ and to assist customers' contextual interaction with the bank for loan and other products. Chat bot "Axis Aha!" is serving on its website.

Yes Bank: Yes Pay Bot, developed in partnership with Payjo - a leading AI banking platform, performs financial transaction in a personalized conversational manner on real time basis. Chat bot "Yes Robot" is serving on its website.

\section{Conclusion:-}

AI is a promising technology, researchers were able to gather rich literature from various data sources, tracking \& analyzing its evaluation, business opportunities, applications etc. and thoroughly analyzed the contribution of various scholars, to find connect with the research objectives as described above, ultimately reaching out to the conclusions to identify the application of AI with specific reference to India's Banking Sector.

The 1st objective of this study was to identify the research work conducted about concept \& application of AI in Banking sector. Researchers have achieved this objective and a detailed description of the same has been presented in Literature Review section, concluding that majority of scholars perceived AI as an extremely useful technology with huge potential of benefiting banking sector by strengthening implementation of its strategies. From implementation perspective, scholars have identified innovation dynamics, determinants and guidelines of AI adoption, diffusion and usage. Scholars have also deliberated upon implications such as security, reliability, privacy etc. consequent to application of AI in banking sector, surveying the state-of-the-art of AI, its architecture, design challenges and hardware prerequisites.

$2^{\text {nd }}$ objective of this study was to examine the state of affairs of AI application in India's Banking sector. Answer to this central research question i.e. 'What role does AI play in successful strategy implementation in India's banking sector' is explored and found “Accenture Banking Technology Vision 2017" report quoting 87 per cent of India's bankers saying that AI can enable banks with intelligent machines which create very human-like customer experience. India's banking sector seems positive about AI as its benefits are visible in positioning banks strongly in multiple strategic areas - Financial (reduction of cost and increase in profitability), Manpower (surveillance, fraud detection, freeing human executives for more value added jobs), Operational (error free, simplified \& automated utilization of resources) and Leadership (optimized decision making, business promotion \& growth, customer delight). Sophisticated algorithms of AI can optimize financial policies, can refine revenue generation models and can develop host of other customized tools for banks. As the conclusion of this study, India's banking sector is surly seen as all set to collaborate with AI to achieve success in its strategy implementation, after all, life is all about keeping pace, evolving and changing with the passage of time.

$3^{\text {rd }}$ objectives of this study was to explore capabilities of AI to deliver differentiated results for successful strategy implementation in India's banking sector. This study has done discussions, deliberations, analysis, a comprehensive review of application of AI and after identifying opportunities as per section 6, it evidences some vital discoveries in this area, urging Banking leadership to review their current state of affairs and finally arriving at actionable opportunities where AI is useful for operations, decision making and improving effectiveness of strategy implementation in various critical areas of banks. Riding on rapid technological advancement, AI is developing at an exponential rate, having capability of overhauling India's banking sector amidst changing trends of present Industry 4.0 era and India's banking sector is no longer having the luxury to apply 'wait \& watch' policy regarding its adoption. If any organization takes such a risk, they shall remain far behind their counterparts because of AI's unique inherent ability to learn, understand \& evolve based on the data already handled, shall belong to the early mover organizations only. AI being one of the best platform in terms of integrity and robustness, banking sector is becoming more and more open to integrate itself with AI, however still a long way is to go before India's banking sector achieves complete maturity level in its integration with AI. 
With reference to the $4^{\text {th }}$ objective of this study, researcher has drawn proactive attention of banking leadership to various strategic aspects of their banks having scope of applying AI, ultimately resulting into better profitability in a sustainable manner, thus providing competitive edge to them. This study has also contributed towards knowledge repository which helps in quickly picking up and applying latest AI innovations in various strategic areas as discussed above in the relevant sections of this paper, and channelizing its manpower towards more value added tasks. Thus it can be concluded that with proactive application of AI in India's banking sector, effectiveness of its strategy implementation can be improved significantly. Authors are hopeful that this study gives a consolidated view of work done on this topic till now and accelerates the momentum of proactive integration of AI in banking sector strategies to handle changing customer preferences in dynamic Industry 4.0 era.

\section{References:-}

1. https://www.financialdirector.co.uk/2019/10/03/ai-for-financial-directors-and-cfos/

2. Aazhvaar, V. (2019). ARTIFICIAL INTELLIGENCE IN INDIAN BANKING SECTOR: CHALLENGES AND OPPORTUNITIES. International Journal of Advanced Research, April 7(5), 1581-1587.

3. Alam, M., \& Khokhar, R. (2006). Impact of Internet on Customer Loyalty in Swedish Banks. J. Econ. Psychol. Apr 7;16:311-29.

4. Ardito, L., Petruzzelli, A. M., Panniello, U., \& Achille, C. (2019). Towards Industry 4.0. Business Process Management Journal, Bradford Vol. 25, Iss. 2, pp: 323-346.

5. Awad, R. (2011). Considerations on Cloud Computing for CPAs. The CPA Journal, New York Vol. 81, Iss. 9, Sep pp: 11-12.

6. Ayachit, M. M. (2017). ICT Innovation in Indian Banking Sector: Trends and Challenges. IOSR Journal of Business and Management (IOSR-JBM), PP 21-27.

7. Bellman, R. (1978). An Introduction to Artificial Intelligence: Can Computers Think? San Francisco: Boyd \& Fraser Pub. Co.

8. Bidgoli, H. (2018). Cloud Computing Deployment: What Have We Learned from Real Life Implementations and Practices. Journal of Strategic Innovation and Sustainability, West Palm Beach Vol. 13, Iss. 1, Jul pp 3652.

9. Brachman, R. J. (2006). (AA)AI More Than the Sum of Its Parts.AI Magazine, Volume 27 Number 4.

10. Brauer, H. (2005). Financial services customer loyalty. Finance Week, March, 49.

11. Brynjolfsson, E., \& Hitt, L. M. (2000). Beyond Computation: Information Technology, Organizational Transformation and Business Performance. Journal of Economic Perspectives, 14(4), 23-48.

12. Castelli, M., Manzoni, L., \& Popovic, A. (2016). An Artificial Intelligence System to Predict Quality of Service in Banking Organizations. Computational Intelligence and Neuroscience, http://dx.doi.org/10.1155/2016/9139380.

13. Chakroborty, A. (2017). Futuristic Robotic Technology in Retail and Banking. Imperial Journal of Interdisciplinary Research (IJIR), ISSN: 2454-1362, Vol-3, Issue-3, 291 - 299.

14. Chester, A. N. (1994). Aligning Technology with Business Strategy. Research-Technology Management, 37(1), 25-32.

15. Davenport, T. (2016). Innovation in Audit Takes the Analytics, AI Routes. Audit Analytics, Cognitive Technologies, to set Accountants Free from Grunt Work. Dupress Publisher.

16. Donner, J., \& Tellez, C. A. (2008). Mobile banking and economic development:linking adoption, impact, and use. Asian Journal of Communication, 18(4), 318-332.

17. Duch, W., Swaminathan, K., \& Meller, J. (2007). Artificial Intelligence Approaches for Rational Drug Design and Discovery, Current Pharmaceutical Design.

18. El-Haddadeh, R. (2019). Digital Innovation Dynamics Influence on Organisational Adoption: The Case of Cloud Computing Services. Information Systems Frontiers, New York, Apr, pp: 1-15.

19. Emerald. (2019). The relationship between cloud adoption and business strategy. Strategic Direction, Bradford Vol. 35, Iss. 4, pp: 7-9.

20. Erdélyi, O. J., \& Goldsmith, J. (2018). Regulating Artificial Intelligence Proposal for a Global Solution. AAAI/ACM Conference on Artificial Intelligence. Ethics and Society.

21. Fethi, M., \& Pasiouras, F. (2010). Assessing Bank Efficiency and Performance with Operational Research and Artificial Intelligence Techniques: A Survey. European Journal of Operational Research, Vol. 204 (2). pp. 189198.

22. Ghodselahi, A., \& Amirmadhi, A. (2011). Application of Artificial Intelligence Techniques for Credit Risk Evaluation. International Journal of Modeling and Optimization, August, Vol. 1, No. 3. pp 243-247. 
23. Ghurair, A. A. (2018, February 3). Embracing artificial intelligence: Do UAE banks have a choice? Khaleej Times, pp. https://www.khaleejtimes.com/business/banking-finance/embracing-artificial-intelligence-do-uaebanks-have-a-choice.

24. Joshi, P. R., Islam, S., \& Islam, S. (2017). A Framework for Cloud Based E-Government from the Perspective of Developing Countries. Future Internet, Basel Vol. 9, Iss. 4, pp: 80.

25. KUMAR, D. N. (2018). A DESCRIPTIVE STUDY ON THE BANKING SYSTEM COHERENT TO VISION 2022: A NEW INDIA. ZENITH International Journal of Business Economics \& Management Research, Vol.8 (4), APRIL (2018), pp. 212-220.

26. Kumar, S., \& Goudar, R. H. (2012). Cloud Computing - Research Issues, Challenges, Architecture, Platforms and Applications: A Survey. International Journal of Future Computer and Communication , Vol. 1, No. 4, December, pp.356-360.

27. Kurode, T. (2018). Review of Applicability of Artificial Intelligence in Various Financial Services in India. Journal of Advance Management Research, ISSN: 2393-9664, Vol.06 Issue-01, January.

28. Kurzweil, R. (1990). The Age of Intelligent Machines. MIT Press.

29. Lagarde, C. J. (2018). Central Banking and Fintech: A Brave New World. Governance, Globalization, 12(1-2), 4-8.

30. Lakshminarayana, P. N., \& Deepthi, B. R. (2019). Advent of Artificial Intelligence and its Impact on Top Leading Commercial Banks in India - Case Study. International Journal of Trend in Scientific Research and Development (IJTSRD), Volume - 3 | Issue - 4 | May-Jun, p 614 - 616.

31. Lee, K. C., \& Chung, N. (2009). Understanding factors affecting trust in and satisfaction with mobile banking in Korea: A modified DeLone and McLean's model perspective. Interacting with Computers, 21(5-6), 385-392.

32. Leimeister, S., Böhm, M., Riedl, C., \& Krcmar, H. (2010). The Business Perspective of Cloud Computing: Actors, Roles and Value Networks. European Conference on Information Systems (p. 56). AIS Electronic Library (AISeL).

33. Longinus, O. (2018). Artificial Intelligence System: Implication for Proper Record Keeping in Microfinance Banks in Nigeria. International Journal of Academic Research in Accounting, Finance and Management Sciences, Vol. 8, No.1, January, pp. 131-136.

34. Low, C., Chen, Y., \& Wu, M. (2011). Understanding the determinants of cloud computing adoption. Industrial Management \& Data Systems , Vol. 111 No. 7, pp. 1006-1023.

35. Mangiuc, D. (2017). Accountants and the cloud - Involving the professionals. Accounting and Management Information Systems, Bucharest Vol. 16, Iss. 1, pp: 179-198.

36. Misra, S. C., \& Mondal, A. (2011). Identification of a company's suitability for the adoption of cloud computing and modelling its corresponding Return on Investment. Mathematical and Computer Modelling , Feb. Vol. 53, pp. 504-21.

37. Moin, K. I., \& Ahmed, Q. B. (2012). Use of Data Mining in Banking. International Journal of Engineering Research and Applications (IJERA), Vol. 2, Issue 2, Mar-Apr, pp.738-742.

38. Moro, S., Cortez , P., \& Paulo, R. (2015). Business Intelligence in Banking. Expert Systems with Applications: An International Journal, Vol. 42(3), pp. 1314-1324.

39. Nanath, K., \& Pillai, R. (2013). A Model for Cost-Benefit Analysis of Cloud Computing. Journal of International Technology and Information Management, San Bernadino Vol. 22, Iss. 3, pp: 95-II.

40. Nuseibeh, Y. H. (2017). Artificial Intelligence: Opportunities and challenges in finance industry. Gulf: Gulf News. Available at: https:/gulfnews.com/business/sectors/banking/artificial-intelligence-opportunities-andchallenges-in-finance-industry-1.1976801.

41. Oztemel, E., \& Samet, G. (2018). Literature review of Industry 4.0 and related technologies. Journal of Intelligent Manufacturing, London (Jul) pp: 1-56.

42. Padhy, R. P., Patra, M. R., \& Satapathy, S. C. (2011). Cloud Computing: Security Issues and Research Challenges. IRACST - International Journal of Computer Science and Information Technology \& Security (IJCSITS), Vol. 1, No. 2, December, pp. 136 - 146.

43. plattform-i40. (2019, April 04). Retrieved from start page / About the platform / Workgroups / Technology and application scenarios: https:/www.plattform-i40.de/PI40/Redaktion/DE/Standardartikel/arbeitsgruppe-02.html

44. Prasad, M., Naik, R. L., \& Bapuji, V. (2013). Cloud Computing : Research Issues and Implications. Institute of Advanced Engineering and Sciencew w w . i a e s jInternational Journal of Cloud Computing and Services Science (IJ-CLOSER), ISSN: 2089-3337, Vol.2, No.2, April, pp. 134 140.

45. Ray, T. (2017). Scopes of Machine Learning and Artificial Intelligence in Banking \& Financial Services. ML \& AI - The Future of Fintechs. December: https://www.stoodnt.com/blog/scopes-of-machine-learning-andartificial-intelligence-in-banking-financials-services-ml-ai-the-future-of-fintechs/. 
46. Ross, P., \& Blumenstein, M. (2013). Cloud computing: the nexus of strategy and technology. The Journal of Business Strategy , Boston Vol. 34, Iss. 4, pp: 39-47.

47. Russell, S., \& Norvig, P. (2003). Artificial Intelligence-A Modern Approach. Dorling Kindersley (India) Pvt. Ltd. pp 16-25, 2nd ed.

48. Sabharwal, M. (2014). The use of Artificial Intelligence (AI) based technological applications by Indian Banks. International Journal of Artificial Intelligence and Agent Technology, 2. 1-5.

49. Sabi, H. M., Uzoka, F.-M. E., Langmia, K., Njeh, F. N., \& Tsuma, C. K. (2018). A cross-country model of contextual factors impacting cloud computing adoption at universities in sub-Saharan Africa. Information Systems Frontiers, New York Vol. 20, Iss. 6, Dec, pp: 1381-1404.

50. Shachmurove, Y. (2002). Applying Artificial Neural Networks to Business, Economics and Finance.

51. Shee, H., Shah, J. M., Fairfield, L., \& Pujawan, N. (2018). The impact of cloud-enabled process integration on supply chain performance and firm sustainability: the moderating role of top management. Supply Chain Management, Bradford Vol. 23, Iss. 6, pp. 500-517.

52. SINDU, M. (2019). ARTIFICIAL INTELLIGENCE AND IT's IMPACT ON BANKING SECTOR. INTERNATIONAL JOURNAL OF RESEARCH IN COMMERCE, IT \& MANAGEMENT, VOLUME NO. 9, ISSUE NO. 01 (JANUARY), 17-19.

53. Sinha, D. M. (2017). ARTIFICIAL INTELLIGENCE -BANKS IN INDIA. International Journal in Management and Social Science, Vol.05 Issue-07, July, 474 - 478.

54. Sophia, M. (2018, January 17). Banks Are Taking Note As Fintech Spikes Customers' Interest. Forbes, pp. https://www.forbesmiddleeast.com/banks-are-taking-note-as-fintech-spikes-customers-interest.

55. Srivastava, P., \& Khan, R. (2018). A Review Paper on Cloud Computing. International Journals of Advanced Research in Computer Science and Software Engineering, ISSN: 2277-128X (Volume-8, Issue-6) pp. 17-20.

56. Technology, N. I. (2011, October 25). Final Version of NIST Cloud Computing Definition Published. Retrieved from https://www.nist.gov/news-events/news/2011/10/final-version-nist-cloud-computing-definition-published

57. Umar, A., Mehmood, A., Majeed, M. F., \& Muham, S. (2019). Innovative Citizen's Services through Public Cloud in Pakistan: User's Privacy Concerns and Impacts on Adoption. Mobile Networks and Applications , New York Vol. 24, Iss. 1, Feb pp: 47-68.

58. VEDAPRADHA, R., \& HARIHARAN, R. (2018). APPLICATION OF ARTIFICIAL INTELLIGENCE IN INVESTMENT BANKS. Review of Economic \& Business Studies, Volume 11, Issue 2, pp.131-136.

59. Vedapradha, R., Ravi, H., \& Jebasingh, R. (2016). TECHNOLOGY IN BUSINESS - A MAGIC WAND IN BANKING SECTOR. INTERNATIONAL JOURNAL OF ENGINEERING SCIENCES \& RESEARCH TECHNOLOGY, $431-435$.

60. Winston, P. H. (1992). Artificial Intelligence. Boston, MA, USA: Addison-Wesley Longman Publishing Co., Inc.

61. Zhang, Q., Cheng, L., \& Boutaba, R. (2010). Cloud computing: state-of-the-art and research challenges. Journal of Internet Services and Applications , May, Volume 1, Issue 1, pp 7-18.

62. Zineldin, M. (2006). The royalty of loyalty: CRM, quality and retention. Journal of consumer marketing, Dec $1 ; 23(7): 430-7$.

63. Sharma, Ashwani and Agarwal, Himanshu (2018). Study of Recent Developments related to Cashless Commerce in India. Journal of Commerce and Trade, October, 2018, 13:2;Pp.:66-71. https://doi.org/10.26703/JCT.v13i2-10. 